\title{
Factors associated with chronic kidney disease in patients with type 2 diabetes in Bangladesh
}

\author{
Sheikh Mohammed Shariful Islam ${ }^{1}{ }^{*}$, Masudus Salehin ${ }^{2}$, Sojib Bin Zaman ${ }^{3}$, Tania Tansi ${ }^{4}$, Rajat Das Gupta ${ }^{5}$, Ling- \\ kan Barua ${ }^{6}$, Palash Chandra Banik ${ }^{6}$ and Riaz Uddin ${ }^{1}$
}

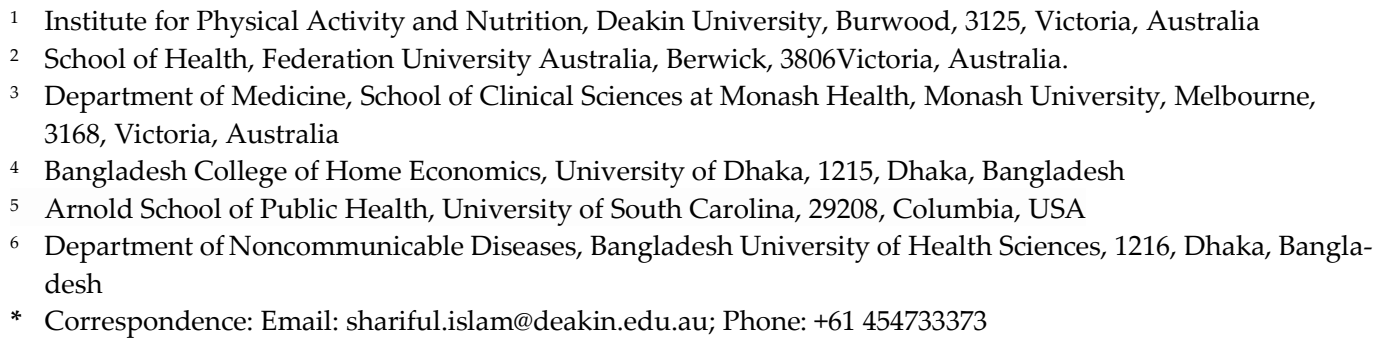

\begin{abstract}
Diabetes and chronic kidney disease (CKD) are a major public health burden in low-andmiddle-income countries. This study aimed to explore factors associated with CKD in patients with type 2 diabetes (T2D) in Bangladesh. A cross-sectional study was conducted among 315 adults with T2D presenting at the outpatient department of Bangladesh Institute of Health Sciences (BIHS) hospital between July 2013 to December 2013. CKD was diagnosed based on estimated Glomerular Filtration Rate using the 'Modification of Diet in Renal Disease' equations and presence of albuminuria estimated by the albumin-to-creatinine ratio. Multivariate logistic regression analysis was used to determine the factors associated with CKD. The overall prevalence of CKD among patients with T2D was $21.3 \%$. In the unadjusted model Factors associated with CKD were: aged 40-49 years (OR: 5.7, 95\% CI: 1.3-25.4), age 50-59 years (7.0, 1.6-39), age $\geq 60$ years $(7.6,1.7-34)$; being female (2.2, 1.2-3.8), hypertensive (1.9, 1.1-3.5) and household income between 10,001-20,000 Bangladeshi taka, BDT $(2.9,1.0-8.2)$ compared with income $\leq 10,000$ BDT. However, after adjustment of other covariates, only duration of hypertension and household income (10,001-20,000 BDT) remained statistically significant. There is a need to implement policies and programs for early detection and management of hypertension and CKD in T2D patients in Bangladesh.
\end{abstract}

Keywords: Type 2 Diabetes Mellitus; Chronic Kidney Diseases; Hypertension; Risk Factors; Bangladesh

\section{Introduction}

Chronic kidney disease (CKD) has been recognized as a global public health burden with increasing prevalence and mortality [1]. In 2017, 1.2 million deaths were due to CKD worldwide [1]. In South Asia, the prevalence of CKD was reported as 13.6\% in Thailand [2], 10.8\% in China [3] , and 15.0\% in India [4]. CKD often leads to progressive end-stage renal disease (ESRD), increased hospitalization and premature deaths [5]. The prevalence of CKD has been increasing in many low-and-middle income countries (LMICs) where there is a lack of health systems capacity for prevention and management. CKD is more prevalent among aged population and is also a common complication for people with diabetes and hypertension. In South Asia, the increasing aging population and rapid urbanization have led to an increase in obesity and diabetes mellitus [6,7]. If this trend continues to rise, it will likely spike the proportion of people with diabetes at a faster rate over the next two decades [6]. Particularly, CKD related to type 2 diabetes (T2D) will rise in parallel [8]. 
Globally, the prevalence of diabetes has increased in many countries over the past thirty years and inevitably, there are proportionally more people with T2D and CKD now than 30 years ago [9]. Diabetes is a major cause of CKD, accounting for about $40 \%$ of new patients [10]. Large-scale epidemiologic surveys have identified several important risk factors for CKD, including old age, presence of T2D, female sex, low socioeconomic status, and use of herbal medicine [11]. Diabetes is a significant risk factor for accelerated progression of CKD towards ESRD, kidney failure and renal replacement therapy [12] and is considered to be a major contributor to chronic vascular diseases. The presence of diabetes in people with CKD deteriorates cardiovascular events [13] and worsens the survival for patients with dialysis or who have undergone kidney transplantation [14].

In recent years, the prevalence of T2D and hypertension is growing rapidly and is expected to increase the prevalence of CKD at an epidemic rate in South Asia $[8,15,16]$. Moreover, CKD causes an increased risk of myocardial infarction, stroke, cardiovascularrelated mortality in patients with T2D in comparison with non-diabetic patients [17]. Early detection of diabetic patients with CKD is important for monitoring cardiovascular risk factors and initiating therapy which can slow down the progression of kidney failure [18]. There have been several reports on the prevalence and risk factors of CKD in patients with T2D in developed countries [11,19]. However, studies on factors associated with CKD in T2D patients are scarce in some developing countries like Bangladesh.

A recent systematic review found that the overall pooled prevalence of CKD among Bangladeshi adults was $17.3 \%$ ranging from $12.8 \%$ to $26.0 \%$ [20]. Another study reported that people with type 2 diabetes in Bangladesh had a high proportion of self-reported kidney disease [21]. A number of studies in Bangladesh have also reported the prevalence of kidney disease in different population groups [22-24]. A few studies have reported on CKD in patients with T2D and its determinants in Bangladesh at community levels [25], slums [26], rural population [27] or during screening [28]. However, information on CKD and its associated factors in T2D patients in urban hospitals is limited. Understanding the factors associated with CKD among people with T2D in urban hospital settings in Bangladesh is essential to develop preventive strategies and improve management practices. Therefore, the aim of this study was to determine the prevalence of CKD among patients with T2D and its associated factors in an urban hospital in Bangladesh.

\section{Materials and Methods}

\subsection{Study design and population}

This cross-sectional analysis is based on the baseline data of the Mobile Phone Intervention for Diabetes (MPID) study in Bangladesh [29]. The data were collected between July 2013 to December 2013. Details on participant selection, assessment process, and clinical data measurement have been described in the study protocol that has been published previously [30]. Briefly, the MPID was a single-center randomized controlled intervention trial to measure the effects of a six-month mobile phone text messaging intervention program on glyceamic control in people with T2D. The inclusion criteria was adult patients with T2D attending the outpatient department of Bangladesh Institute of Health Sciences Hospital (BIHS), owning a mobile phone and willing to receive a text messaging program on lifestyle behaviour change for six months. The BIHS hospital serves more than 2 million people living in Dhaka city and surrounding areas in Bangladesh. All potential eligible patients referred by an attending BIHS physician and providing written informed consent were screened for eligibility and baseline data and blood samples were collected.

\subsection{Data collection and process}

All patients underwent a structured interview to collect information on socio-demographics, including age, sex, household income and education; time of diabetes onset and duration; presence and duration of hypertension; status of fasting plasma glucose (FPG), two-hour post prandial glucose (2h PPG) and glycated haemoglobin (HbA1c); blood pressure (BP) readings, and lipid-lowering therapy, with an indication of the 
type/class of drug/medication (antihypertensive, anti-dyslipidemia, oral antihyperglycemic agents, etc.).

\subsection{Measurements and definitions:}

Body weight and height of the participants were measured to the nearest $0.1 \mathrm{~kg}$ and $0.1 \mathrm{~cm}$, respectively, using a standard protocol [30] and were used to calculate the body mass index (BMI; in $\mathrm{kg} / \mathrm{m}^{2}$ ). BP was measured three times by a trained physician using a digital sphygmomanometer (Omron, SEM-1, Omron Corp, Osaka, Japan) in a sitting position after patients had taken five minutes rest and five minutes interval between the records. The mean of the last two measures was used to define BP status. Hypertension was defined by systolic BP $\geq 140 \mathrm{mmHg}$ and/or diastolic $\mathrm{BP} \geq 90 \mathrm{mmHg}$ and/or ongoing anti-hypertensive treatment. Glycated Haemoglobin (HbA1c) was measured by high-performance liquid chromatography using Diabetes Control and Complications Trial (DCCT) aligned methods. Serum triglycerides (TG), total cholesterol (TC) and high-density lypoprotein (HDL) cholesterol were determined by colorimetric enzymatic methods; LDL cholesterol was calculated by the Friedwald formula, i.e.: LDL-cholesterol (in $\mathrm{mmol} / \mathrm{L}$ ) $=\mathrm{TC}-$ [HDL-cholesterol + (TG/2.17)]. Diabetes was defined according to WHO criteria as fasting plasma glucose values of $\geq 7.0 \mathrm{mmol} / \mathrm{L}(126 \mathrm{mg} / \mathrm{dl})$, 2-h post-prandal plasma glucose $\geq 11.1$ $\mathrm{mmol} / \mathrm{L}(200 \mathrm{mg} / \mathrm{dl}), \mathrm{HbA} 1 \mathrm{c} \geq 6.5 \%(48 \mathrm{mmol} / \mathrm{l})$; or a random plasma glucose $\geq 11.1 \mathrm{mmol} / \mathrm{L}$ $(200 \mathrm{mg} / \mathrm{dl})$ in the presence of signs and symptoms of diabetes [31].

The presence of CKD was assessed using the most recent urinary albumin and serum creatinine reports extracted from patient's medical report during the last 12 months. We included reports where the tests were performed at BIHS hospital to avoid measurement bias. Estimated Glomerular Filtration Rate (eGFR) was calculated using the Modification of Diet in Renal Disease (MDRD) equations [32]. Patients with eGFR $<60 \mathrm{~mL} / \mathrm{min} / 1.73 \mathrm{~m}^{2}$ present for three months or more and/or markers of kidney damage determined by the presence of albuminuria estimated by the albumin-to-creatinine ratio were defined as CKD according to The National Kidney Foundation's Kidney Disease Outcomes Quality Initiative [33].

\subsection{Data analysis:}

Statistical analyses were conducted using SPSS 21 (IBM Corporation, USA). Continuous data were expressed as the mean \pm standard deviation (SD), or median and interquartile ranges, and categorical data were presented as number with percentages. Kolmogorov-Smirnov test was used to check normality for the continuous variables. We compared the mean and median between groups using t-test and Mann-Whitney $U$ test, respectively. We used multiple logistic regressions to explore the factors associated with CKD. We identified factors which had a bivariate association with CKD at $20 \%$ level of significance $(p \leq .20)$. We checked these variables for collinearity issues, and those without any collinearity were entered into the multivariable model. We expressed associations as odds ratio (OR) with $95 \%$ confidence intervals (CI). We considered a p-value of $<0.05$ as significant.

\subsection{Ethics:}

The study was conducted following the Declaration of Helsinki and the protocol was approved by the Research Review Committee and Ethical Review Committee of the International Center for Diarrhoeal Disease Research, Bangladesh (icddr,b) (approval number PR \#13018). Written informed consent was obtained from all the participants. Permission was granted from the Director of BIHS hospital for using their facility for data collection.

\section{Results}

Overall, 500 patients were recruited, of which 185 (37\%) had missing data on renal function and were excluded from the present analyses. Therefore, the analytical sample 
for this analysis was 315 participants with complete information on renal function as assessed by serum creatinine and albuminuria measurements.

\subsection{Characteristics of the patients}

The mean \pm SD age of the patients was $50.7 \pm 9.9$ years. Patients with CKD were on average 4.6 years older than non-CKD patients $(p<0.001)$. CKD were more common in females with T2D than males, $54.3 \%$ and $68.7 \%$, respectively. The median income of the patients with T2D was 35,000 BDT (equivalent to US\$448.7). The education level of the majority of the patients with T2D (41.0\%) was a higher secondary certificate or above. CKD was more common in patients with a secondary level of education $(37.3 \%)$, and most non-CKD patients had a higher secondary level of education (44.4\%) (Table 1).

More than one-third (38.4) of the patients had diabetes for $\geq 5$ years; however, CKD was more common (55.2\%) among those who had diabetes for $<5$ years. The mean FPG was $7.6 \pm 2.1 \mathrm{mmol} / \mathrm{L}$ among the T2D patients; however, the average FPG in CKD patients was about $0.6 \mathrm{mmol} / \mathrm{L}$ less than the non-CKD patients' group. This study found that 2-h PPG was uncontrolled in majority of patients with T2D (53.8\%). Moreover, about half $(45.9 \%)$ of the patients were in a poorly controlled glycemic state (HbA1c $>8 \%)$. Most of the T2D patients were hypertensive $(60.0 \%)$. Duration of HTN was $>5$ years in the majority of T2D patients $(54.6 \%)$ and CKD was more common among this group. Most of the patients with T2D were obese $(87.8 \%)$.

Table 1. Basic characteristics of the study participants $(\mathrm{N}=315)$.

\begin{tabular}{|c|c|}
\hline Variables & $\mathbf{N}(\%)$ \\
\hline \multicolumn{2}{|l|}{ Age (years) } \\
\hline Mean $\pm S D$, years & $50.7 \pm 9.9$ \\
\hline$<40$ & $44(14.0)$ \\
\hline $40-49$ & $103(32.7)$ \\
\hline $50-59$ & $104(33.0)$ \\
\hline$\geq 60$ & $64(20.3)$ \\
\hline \multicolumn{2}{|l|}{ Gender } \\
\hline Male & $144(45.7)$ \\
\hline Female & $171(54.3)$ \\
\hline \multicolumn{2}{|l|}{ Household income (BDT) } \\
\hline$\leq 10000$ BDT & $36(11.8)$ \\
\hline 10001-20000 BDT & $94(30.8)$ \\
\hline 20001-30000 BDT & $52(17.0)$ \\
\hline 30001-40000 BDT & $29(9.5)$ \\
\hline 40001-50000 BDT & $39(12.8)$ \\
\hline$>50000 \mathrm{BDT}$ & $55(18.0)$ \\
\hline \multicolumn{2}{|l|}{ Education } \\
\hline No academic education & $40(12.7)$ \\
\hline Primary (year 5 completed) & $53(16.8)$ \\
\hline Secondary (year 10 completed) & $93(29.5)$ \\
\hline $\begin{array}{l}\text { Higher secondary \& above (year } 12 \text { and above } \\
\text { completed) }\end{array}$ & $129(41.0)$ \\
\hline \multicolumn{2}{|l|}{ Duration of diabetes (years) } \\
\hline Median (IQR) duration: 3.0 (1.0-7.0) & \\
\hline
\end{tabular}




\begin{tabular}{|l|c|}
\hline$<5$ Years & $194(61.6)$ \\
\hline$\geq 5$ Years & $121(38.4)$ \\
\hline Duration of hypertension (years) & \\
\hline Median (IQR) duration: $5.0(2.0-10.0)$ & $83(45.4)$ \\
\hline$<5$ Years & $100(54.6)$ \\
\hline$\geq 5$ Years & \\
\hline FBS $(\mathbf{m m o l} / \mathrm{L})$ & $7.6 \pm 2.1$ \\
\hline Mean \pm SD. & $114(36.9)$ \\
\hline Optimal $<6.7 \mathrm{mmol} / 1$ & $84(27.2)$ \\
\hline Fair $6.7-7.8 \mathrm{mmol} / 1$ & $111(35.9)$ \\
\hline Poor $>7.8 \mathrm{mmol} / \mathrm{l}$ & $141(46.2)$ \\
\hline 2h AFB $(\mathbf{m m o l} / \mathrm{L})$ & $164(53.8)$ \\
\hline Control $<10.0 \mathrm{mmol} / 1$ & \\
\hline Uncontrolled $\geq 10.0 \mathrm{mmol} / 1$ & $56(28.9)$ \\
\hline HbA1c $(\%)$ & $49(25.3)$ \\
\hline Optimal $<7 \%$ & $89(45.9)$ \\
\hline Fair $7-8 \%$ & \\
\hline Poor $>8 \%$ & $7(2.2)$ \\
\hline Obesity & $308(97.8)$ \\
\hline Not obese & $126(40.0)$ \\
\hline Obese & $189(60.0)$ \\
\hline Hypertension & \\
\hline Absent & \\
\hline Present & \\
\hline
\end{tabular}

*FBS: Fasting Blood Sugar, BDT: Bangladeshi Taka, 10,000 BDT= \$128.2 [1\$=78 BDT], IQR: interquartile range. HbA1c: Glycated Haemoglobin; 2h ABF: Blood sugar 2 hours after breakfast.

\subsection{Prevalence of $C K D$ :}

The overall prevalence of CKD among patients with T2D was $21.3 \%$, which was higher among females $(68.7 \%)$ compared to males $(31.3 \%)$. FBS was optimal $(<6.7 \mathrm{mmol} / \mathrm{L})$ in most of the diabetic patients with CKD (47.7\%). However, there was no significant difference in $2 \mathrm{hABF}$ in these patients. Around $97.0 \%$ of CKD patients with T2D were obese and $71.6 \%$ were hypertensive. CKD was more common in patients with a secondary level of education $(37.3 \%)$ than patients who studied less than or higher than the secondary level.

Table 2. Bivariate results of factors associated with CKD in T2D patients (N=315).

\begin{tabular}{|l|c|c|c|c|}
\hline Variables & $\begin{array}{c}\text { CKD } \\
(\mathbf{n = 6 7 )} \\
\mathbf{n}(\mathbf{\%})\end{array}$ & $\begin{array}{c}\text { Non-CKD } \\
\mathbf{( n = 2 4 8 )} \\
\mathbf{n}(\mathbf{\%})\end{array}$ & $\begin{array}{c}\text { Unadjusted OR } \\
\mathbf{( 9 5 \%} \mathbf{C I})\end{array}$ & P-Value \\
\hline Age (years) & & & & \\
\hline$<40$ & $2(3.0)$ & $42(16.9)$ & Reference & \\
\hline $40-49$ & $22(32.8)$ & $81(32.7)$ & $5.7(1.3-25.4)$ & 0.02 \\
\hline $50-59$ & $26(38.8)$ & $78(31.5)$ & $7.0(1.6-30.9)$ & 0.01 \\
\hline$\geq 60$ & $17(25.4)$ & $47(19.0)$ & $7.6(1.7-34.8)$ & 0.01 \\
\hline
\end{tabular}




\begin{tabular}{|c|c|c|c|c|}
\hline \multicolumn{5}{|l|}{ Gender } \\
\hline Male & $21(31.3)$ & $123(49.6)$ & Reference & \\
\hline Female & $46(68.7)$ & $125(50.4)$ & $2.2(1.2-3.8)$ & 0.01 \\
\hline \multicolumn{5}{|l|}{$\begin{array}{l}\text { Household income } \\
\text { (BDT) }\end{array}$} \\
\hline$\leq 10000 \mathrm{BDT}$ & $5(7.8)$ & $31(12.9)$ & Reference & \\
\hline 10001-20000 BDT & $30(46.9)$ & $64(26.6)$ & $2.9(1.0-8.2)$ & 0.04 \\
\hline 20001-30000 BDT & $9(14.1)$ & $43(17.8)$ & $1.3(0.4-4.3)$ & 0.67 \\
\hline 30001-40000 BDT & $5(7.8)$ & $24(10.0)$ & $1.3(0.3-5.0)$ & 0.71 \\
\hline 40001-50000 BDT & $9(14.1)$ & $30(12.4)$ & $1.9(0.6-6.2)$ & 0.31 \\
\hline$>50000 \mathrm{BDT}$ & $6(9.4)$ & $49(20.3)$ & $0.8(0.2-2.7)$ & 0.67 \\
\hline \multicolumn{5}{|l|}{ Education } \\
\hline $\begin{array}{l}\text { No academic } \\
\text { education }\end{array}$ & $7(10.4)$ & 33 (13.3) & Reference & \\
\hline Primary & $16(23.9)$ & $37(14.9)$ & $2.0(0.7-5.6)$ & 0.17 \\
\hline Secondary & $25(37.3)$ & $68(27.4)$ & $1.7(0.7-4.4)$ & 0.25 \\
\hline $\begin{array}{l}\text { Higher secondary \& } \\
\text { above }\end{array}$ & $19(28.4)$ & $110(44.4)$ & $0.8(0.3-2.1)$ & 0.67 \\
\hline \multicolumn{5}{|l|}{$\begin{array}{l}\text { Duration of diabetes } \\
\text { (years) }\end{array}$} \\
\hline$<5$ Years & $37(55.2)$ & 157 (63.3) & Reference & \\
\hline$\geq 5$ Years & $30(44.8)$ & $91(36.7)$ & $1.4(0.8-2.4)$ & 0.23 \\
\hline \multicolumn{5}{|l|}{$\begin{array}{l}\text { Duration of } \\
\text { hypertension (years) }\end{array}$} \\
\hline$<5$ Years & $18(35.3)$ & $65(49.2)$ & Reference & \\
\hline$\geq 5$ Years & $33(64.7)$ & $67(50.8)$ & $1.8(0.9-3.5)$ & 0.09 \\
\hline \multicolumn{5}{|l|}{ FPG (mmol/L) } \\
\hline Optimal <6.7 mmol/1 & $31(47.7)$ & $83(34.0)$ & Reference & \\
\hline Fair $6.7-7.8 \mathrm{mmol} / 1$ & $18(27.7)$ & $66(27.0)$ & $0.7(0.4-1.4)$ & 0.35 \\
\hline Poor $>7.8 \mathrm{mmol} / 1$ & $16(24.6)$ & $95(38.9)$ & $0.5(0.2-0.9)$ & 0.02 \\
\hline \multicolumn{5}{|l|}{ 2-h PPG (mmol/L) } \\
\hline Control $<10.0 \mathrm{mmol} / 1$ & $32(50.8)$ & $109(45.0)$ & Reference & \\
\hline $\begin{array}{l}\text { Uncontrolled } \geq 10.0 \\
\mathrm{mmol} / 1\end{array}$ & $31(49.2)$ & $133(55.0)$ & $0.8(0.5-1.4)$ & 0.42 \\
\hline \multicolumn{5}{|l|}{ HbA1c (\%) } \\
\hline Optimal $<7 \%$ & $12(36.4)$ & $44(27.3)$ & Reference & \\
\hline Fair $7-8 \%$ & $9(27.3)$ & $40(24.8)$ & $0.8(0.3-2.2)$ & 0.70 \\
\hline Poor $>8 \%$ & $12(36.4)$ & $77(47.8)$ & $0.6(0.2-1.4)$ & 0.21 \\
\hline \multicolumn{5}{|l|}{ Obesity } \\
\hline Not obese & $2(3.0)$ & $5(2.0)$ & Reference & \\
\hline Obese & $65(97.0)$ & $243(98.0)$ & $0.7(0.1-3.5)$ & 0.64 \\
\hline Hypertension & & & & \\
\hline
\end{tabular}




\begin{tabular}{|l|l|c|c|c|}
\hline Absent & $19(28.4)$ & $107(43.1)$ & Reference & \\
\hline Present & $48(71.6)$ & $141(56.9)$ & $1.9(1.1-3.5)$ & 0.03 \\
\hline
\end{tabular}

*FBS: Fasting Plasma Glucose; 2-h PPG: 2 hours post prandal glucose; HbA1c: glycated haemoglobin; BDT: Bangladeshi Taka, 10,000 BDT= $\$ 128.2[1 \$=78 \mathrm{BDT}]$.

\subsection{Results of bivariate analysis:}

Table 2 presents the bi-variable regression analysis of factors associated with CKD. Older patient groups had significantly greater chances of having CKD compared to young patients' group: Compared to patients aged <40 years, patients in the age group 40-49 years had more than 5 times higher odds of developing CKD ( $p=0.02)$, for patients in age group $\geq 60$ years, the odds were 7.6 times higher $(p=0.01)$. Females had 2.2 times higher odds of having CKD when compared with male patients $(\mathrm{p}<0.01)$. This study found that the odds of developing CKD among hypertensive diabetic patients were higher than the normotensive diabetic patients $(p=0.03$ ). However, the duration of diabetes $(<5$ or $\geq 5$ years) was not significantly associated with CKD in our patient groups $(p=0.09)$.

\subsection{Results of multivariate analysis:}

Table 3 presents the multivariate analysis of factors associated with CKD. We found only two factors that were statistically and significantly associated with CKD. Diabetic patients with a household income of 10-20 thousand BDT had higher odds of having CKD $(\mathrm{OR}=4.12 ; 95 \%$ CI 1.12-15.20) than those with lesser income. Duration of hypertension was found to be associated with higher odds of CKD, i.e., with one-year increase in the duration of hypertension among patients with T2D, the odds of developing CKD was 6\% higher (OR 1.06; CI 1.00-1.12).

Table 3. Multivariate analysis of factors associated with CKD in T2D patients.

\begin{tabular}{|c|c|c|}
\hline Variables & OR $(95 \%$ CI) & p-value \\
\hline \multicolumn{3}{|l|}{ Age (years) } \\
\hline$<40$ & Reference & \\
\hline $40-49$ & $2.82(0.52-15.32)$ & 0.231 \\
\hline $50-59$ & $2.50(0.45-13.96)$ & 0.295 \\
\hline$\geq 60$ & $2.51(0.40-15.70)$ & 0.327 \\
\hline \multicolumn{3}{|l|}{ Gender } \\
\hline Male & Reference & \\
\hline Female & $1.76(0.78-3.97)$ & 0.177 \\
\hline \multicolumn{3}{|l|}{ Household income (BDT) } \\
\hline$\leq 10000$ BDT & Reference & \\
\hline 10001-20000 BDT & $4.12(1.12-15.20)$ & 0.033 \\
\hline 20001-30000 BDT & $2.06(0.48-8.88)$ & 0.331 \\
\hline 30001-40000 BDT & $1.19(0.21-6.65)$ & 0.842 \\
\hline 40001-50000 BDT & $1.43(0.31-6.62)$ & 0.649 \\
\hline$>50000 \mathrm{BDT}$ & $0.71(0.15-3.38)$ & 0.664 \\
\hline Duration of hypertension (years) & $1.06(1.00-1.12)$ & 0.049 \\
\hline FPG (mmol/L) & $0.97(0.81-1.17)$ & 0.763 \\
\hline \multicolumn{3}{|l|}{ Hypertension } \\
\hline Absent & Reference & \\
\hline Present & $1.56(0.56-4.35)$ & 0.392 \\
\hline
\end{tabular}

*FBS: Fasting Plasma Glucose; BDT: Bangladeshi Taka, 10,000 BDT= US\$ 128.2 [1 US\$=78 BDT]. 


\section{Discussion}

To the best of our knowledge, this is the first study that estimated the prevalence of CKD and its associated factors in patients with T2D attending an urban hospital in Bangladesh. Almost one in five people with T2D in urban Bangladesh had CKD, which was almost twice common in females than males. The key finding of our study is that household income and duration of hypertension were significantly associated with CKD in our study population. The CKD prevalence in our study is similar to a previous study conducted in Thailand where one-fifth of the participants with T2D attending a district hospital for diabetic care had CKD[34] . In Nepal, 20.3\% patients with T2D reported having CKD [35]. Studies conducted in other South Asian and developing countries reported a relatively higher prevalence. For example, CKD prevalence was 31.5\% in Pakistan [36] and $24.7 \%$ in Tanzania [37]. However, our finding was in contrast with the DEMAND study that assessed markers of CKD in 32,208 patients in a referred, clinic-based or officebased setting across 33 countries and found $~ 50 \%$ of patients with T2D without a known history of proteinuria and/or diabetic kidney disease had CKD [38]. These discrepancies might be due to the difference in population health, geographic locations, methods of CKD diagnosis, quality of diabetes care and available resources for management of T2D.

Hypertension is common in patients with CKD and those with T2D. Hypertension is a classical risk factor of kidney injury, and uncontrolled hypertension plays an important role in the progression of CKD by increasing glomerular filtration pressure and subsequent renal damage [39]. Patients with T2D may have hypertension for years prior to the onset of overt diabetes. Furthermore, people with diabetes have shown low medication adherence in Bangladesh which exposes them to increased risks of diabetes complications [40-42]. Still, if BP rises further, those patients are subsequently likely to develop CKD and diabetic nephropathy. The community-based study of CKD among T2D patients in Taiwan showed that the presence and duration of hypertension were both significantly associated with proteinuria and renal impairment after controlling for covariates [43]. Apart from showing a higher prevalence of CKD in patients with hypertension $(71.6 \%)$ in our study, the duration of hypertension among our population was also significantly associated with CKD after adjustment of all covariates, which is supported by study by Thakur et al. in Nepal [35] that showed significant association of high BP with microalbuminuria. Previous studies also showed a positive correlation between these two variables [44,45].

CKD is increasingly common in low-and-middle income countries, mostly due to a lack of healthcare infrastructures and resources for diagnosis and management, health insurance and limited healthcare access [46]. Poverty is one of the most important markers of poor health and chronic diseases, including CKD [47]. Our results showed that participants with household incomes between BDT 10,001-20,000 had almost four times the odds of having CKD compared to those with household incomes $<$ BDT 10,000. This might be due to the fact that low income groups avoid healthcare services as they cannot afford the high costs of treatment and also higher prevalence of hypertension among high-income groups in Bangladesh [48,49]. Our results contrast with a large registry based study in India, where CKD was significantly lower in the highest income group [50].

Ageing is considered the most common cause of renal impairment in patients with T2D and with global increase in life expectancy, the prevalence of CKD is expected to rise [51]. Our study found a non-significant association between aging and CKD. Previous studies have shown a higher prevalence of CKD in females [43,52], consistent with our findings. In our study, CKD was more prevalent $(55.2 \%)$ in patients with diabetes $<5$ years, reflecting on the early onset of CKD in patients with T2D, although the relationship was not statistically significant. However, a study in Nepal [35] reported a positive correlation of microalbuminuria with duration ( $>5$ years) of diabetes mellitus. Similar findings have been observed by Idowu et al., and Varghese et al., who reported the duration of diabetes as a major predictor of microalbuminuria [53,54].

Our study had a number of limitations. First, we used a cross-sectional study design; therefore, we could not establish any causal relationship between CKD and its risk factors. Second, data were collected from a single hospital setting in Dhaka city and are not 
representative of the Bangladeshi population. Moreover, the study had a relatively small sample size, which may have limited the generalisability of the findings to other T2D patients in Bangladesh; hence, the results should be interpreted with caution. Third, data for this study were collected in 2013. There have been considerable changes in sociodemographic and economic conditions of the country and health behaviours of its population, which may have impact on T2D and CKD in Bangladesh. Therefore, studies with more recent data are required. Fourth, urinary albumin and serum creatinine data were obtained from patient's medical report for tests conducted at BIHS hospital only and thus, participants who tested in other facilities or did not have updated reports were excluded. Fifth, in the current study other factors such as history of atrial fibrillation, coronary artery disease, or heart failure, which may contribute to T2D and CKD have not been assessed. Finally, as with any cross-sectional study with self-reported data, recall bias or reporting bias could be a problem. Nevertheless, the findings of this study could shed light on future study design and more extensive studies with more robust measurements and follow-up.

Our study was conducted in an urban tertiary level hospital where one-fifth of the diabetic patients had CKD despite the availability of a wide range of healthcare services and facilities, for example, multidisciplinary specialists, counsellors, and research labs. This might also reflect the harsh scenario of rural population in Bangladesh or similar country settings where patients with T2D remain undiagnosed for an extended period of time and eventually appear to the hospital when they have already developed macro or micro vascular complications [42,55]. Strategies for early detection of CKD and hypertension with innovative approaches to management is needed in patients with T2D in Bangladesh [56-62].

\section{Conclusion}

In conclusion, we found that more than one in five adults with T2D attending an urban hospital in Bangladesh had CKD. Higher household income and hypertension were associated with CKD in patients with T2D. There is an urgent need for collective efforts for the prevention, early detection and management of hypertension and CKD in T2D patients in Bangladesh.

Funding: This research study was supported by the icddr,b and the Center for International Health $(\mathrm{CIH})$, Ludwig-Maximilians-Universitat, Munich, Germany through DAAD, BMZ and Exceed.

Acknowledgments: We acknowledge with gratitude the commitment of DAAD, BMZ and Exceed to support our research. We would like to thank the BIHS staff for their overall support. We also thank study participants and the study team for their valuable support for this research.

Author Contributions: Conceptualization, S.M.S.I; formal analysis, S.M.S.I and R.U.; funding acquisition, S.M.S.I.; investigation, S.M.S.I; methodology, S.M.S.I. and R.U.; project administration, S.M.S.I.; resources, S.M.S.I.; writing - original draft, S.M.S.I., R.U., M.S., R.J. and S.B.Z.; writingreview and editing, T.T., R.D.G., L.B. and P.C.B. All authors have read and agreed to the published version of the manuscript.

Institutional Review Board Statement: The study was approved by the Research Review Committee and Ethical Review Committee of the International Center for Diarrhoeal Disease Research, Bangladesh (icddr,b).

Informed Consent Statement: Written informed consent was obtained from all the participants.

Data Availability Statement: The data presented in this study are available on request from the corresponding author.

Conflicts of Interest: The authors declare no conflict of interest.

\section{References}

1. Bikbov, B.; Purcell, C.A.; Levey, A.S.; Smith, M.; Abdoli, A.; Abebe, M.; Adebayo, O.M.; Afarideh, M.; Agarwal, S.K.; AgudeloBotero, M. Global, regional, and national burden of chronic kidney disease, 1990-2017: a systematic analysis for the Global Burden of Disease Study 2017. Lancet 2020, 395, 709-733. 
2. Jha, V. Current status of chronic kidney disease care in southeast Asia. Seminars in Nephrology 2009, 29, 487-496.

3. Zhang, L.; Wang, F.; Wang, L.; Wang, W.; Liu, B.; Liu, J.; Chen, M.; He, Q.; Liao, Y.; Yu, X. Prevalence of chronic kidney disease in China: a cross-sectional survey. Lancet 2012, 379, 815-822.

4. Varma, P.P.; Raman, D.K.; Ramakrishnan, T.; Singh, P.; Varma, A. Prevalence of early stages of chronic kidney disease in apparently healthy central government employees in India. Nephrology Dialysis Transplantation 2010, 25, 3011-3017.

5. Mills, K.T.; Xu, Y.; Zhang, W.; Bundy, J.D.; Chen, C.-S.; Kelly, T.N.; Chen, J.; He, J. A systematic analysis of worldwide population-based data on the global burden of chronic kidney disease in 2010. Kidney International 2015, 88, 950-957.

6. $\quad$ Ebrahim, S.; Kinra, S.; Bowen, L.; Andersen, E.; Ben-Shlomo, Y.; Lyngdoh, T.; Ramakrishnan, L.; Ahuja, R.; Joshi, P.; Das, S.M. The effect of rural-to-urban migration on obesity and diabetes in India: a cross-sectional study. PLoS Medicine 2010, 7, e1000268.

7. Islam, S.M.S.; Purnat, T.D.; Phuong, N.T.A.; Mwingira, U.; Schacht, K.; Fröschl, G. Non-Communicable Diseases (NCDs) in developing countries: a symposium report. Globalization and Health 2014, 10, 1-8.

8. Abraham, G.; Varughese, S.; Thandavan, T.; Iyengar, A.; Fernando, E.; Naqvi, S.; Sheriff, R.; Ur-Rashid, H.; Gopalakrishnan, N.; Kafle, R.K. Chronic kidney disease hotspots in developing countries in South Asia. Clinical Kidney Journal 2016, 9, 135-141.

9. Guariguata, L.; Whiting, D.R.; Hambleton, I.; Beagley, J.; Linnenkamp, U.; Shaw, J.E. Global estimates of diabetes prevalence for 2013 and projections for 2035. Diabetes Research and Clinical Practice 2014, 103, 137-149.

10. Levey, A.S.; Coresh, J. Chronic kidney disease. Lancet 2012, 379, 165-180.

11. Jha, V.; Garcia-Garcia, G.; Iseki, K.; Li, Z.; Naicker, S.; Plattner, B.; Saran, R.; Wang, A.Y.-M.; Yang, C.-W. Chronic kidney disease: global dimension and perspectives. Lancet 2013, 382, 260-272.

12. Ortiz, A.; Covic, A.; Fliser, D.; Fouque, D.; Goldsmith, D.; Kanbay, M.; Mallamaci, F.; Massy, Z.A.; Rossignol, P.; Vanholder, R. Epidemiology, contributors to, and clinical trials of mortality risk in chronic kidney failure. lancet 2014, 383, $1831-1843$.

13. Go, A.S.; Chertow, G.M.; Fan, D.; McCulloch, C.E.; Hsu, C.-y. Chronic kidney disease and the risks of death, cardiovascular events, and hospitalization. New England Journal of Medicine 2004, 351, 1296-1305.

14. Foley, R.N.; Murray, A.M.; Li, S.; Herzog, C.A.; McBean, A.M.; Eggers, P.W.; Collins, A.J. Chronic kidney disease and the risk for cardiovascular disease, renal replacement, and death in the United States Medicare population, 1998 to 1999 . Journal of the American Society of Nephrology 2005, 16, 489-495.

15. Jha, V. ESRD burden in South Asia: the challenges we are facing. Global Health 2015, $219,221$.

16. Al-Zubayer, M.A.; Ahammed, B.; Sarder, M.A.; Kundu, S.; Majumder, U.K.; Islam, S.M.S. Double and triple burden of noncommunicable diseases and its determinants among adults in Bangladesh: Evidence from a recent demographic and health survey. International Journal of Clinical Practice 2021, 75, e14613.

17. Gerstein, H.C.; Mann, J.F.; Yi, Q.; Zinman, B.; Dinneen, S.F.; Hoogwerf, B.; Hallé, J.P.; Young, J.; Rashkow, A.; Joyce, C. Albuminuria and risk of cardiovascular events, death, and heart failure in diabetic and nondiabetic individuals. JAMA 2001, 286, 421-426.

18. Hahr, A.J.; Molitch, M.E. Management of diabetes mellitus in patients with chronic kidney disease. Clinical Diabetes and Endocrinology 2015, 1, 2.

19. Islam, S.; Islam, M.; Rawal, L.; Mainuddin, A.; Wahiduzzaman, M.; Niessen, L. Clinical profile of patients with diabetic nephropathy in a tertiary level hospital in Dhaka, Bangladesh. Archieves of Medicine and Health Science 2015, 3, 191-198.

20. Hasan, M.; Sutradhar, I.; Gupta, R.D.; Sarker, M. Prevalence of chronic kidney disease in South Asia: a systematic review. BMC Nephrology 2018, 19, 291.

21. Islam, S.M.S.; Alam, D.S.; Wahiduzzaman, M.; Niessen, L.W.; Froeschl, G.; Ferrari, U.; Seissler, J.; Rouf, H.; Lechner, A. Clinical characteristics and complications of patients with type 2 diabetes attending an urban hospital in Bangladesh. Diabetes E Metabolic Syndrome: Clinical Research \& Reviews 2015, 9, 7-13.

22. Hasan, M.J.; Muqueet, A.; Sharmeen, A.; Rahman, M.; Ahmed, T.U.; Haque, A.; Quddush, A.R.; Bari, M.A. Prevalence of Diabetes mellitus, Hypertension and Proteinuria in a Rural area of Bangladesh. Community Based Medical Journal 2012, 1, 8-13. 
23. Karim, A.; Das, D.; Salahuddin, M.; Marjan, G.; Islam, M.; Shaha, A.; Gupta, R.; Islam, S.; Amin, R.; Rashid, H. Prevalence of microalbuminuria and overt proteinuria in hypertension and their relations with renal function in a rural population of Bangladesh. Bangladesh Journal of Medicine 2013, 24, 59-64.

24. Feng, L.; de Silva, H.A.; Jehan, I.; Naheed, A.; Kasturiratne, A.; Himani, G.; Hasnat, M.A.; Jafar, T.H. Regional variation in chronic kidney disease and associated factors in hypertensive individuals in rural South Asia: findings from control of blood pressure and risk attenuation-Bangladesh, Pakistan and Sri Lanka. Nephrology Dialysis Transplantation 2019, 34, $1723-1730$.

25. Anand, S.; Khanam, M.A.; Saquib, J.; Saquib, N.; Ahmed, T.; Alam, D.S.; Cullen, M.R.; Barry, M.; Chertow, G.M. High prevalence of chronic kidney disease in a community survey of urban Bangladeshis: a cross-sectional study. Globalization and Health 2014, 10, 9.

26. Huda, M.N.; Alam, K.S. Prevalence of chronic kidney disease and its association with risk factors in disadvantageous population. International Journal of Nephrology 2012, 2012.

27. Rahim, M.A.; Mitra, P.; Haque, H.F.; Samdani, T.S.; Zaman, S.; Uddin, K.N. Prevalence of chronic kidney disease stages 3-5 among patients with type 2 diabetes mellitus in Bangladesh. IMC Journal of Medical Science 2017, 11, 19-24.

28. Fatema, K.; Abedin, Z.; Mansur, A.; Rahman, F.; Khatun, T.; Sumi, N.; Kobura, K.; Akter, S.; Ali, L. Screening for chronic kidney diseases among an adult population. Saudi Journal of Kidney Diseases and Transplantation 2013, $24,534$.

29. Islam, S.M.S.; Niessen, L.W.; Ferrari, U.; Ali, L.; Seissler, J.; Lechner, A. Effects of Mobile Phone SMS to Improve Glycemic Control Among Patients With Type 2 Diabetes in Bangladesh: A Prospective, Parallel-Group,Randomized Controlled Trial. Diabetes Care 2015, 2015, 112-113.

30. Islam, S.M.S.; Lechner, A.; Ferrari, U.; Froeschl, G.; Alam, D.S.; Holle, R.; Seissler, J.; Niessen, L.W. Mobile Phone Intervention for Increasing Adherence to Treatment for Type 2 Diabetes in an Urban Area of Bangladesh: Protocol for a Randomized Controlled Trial BMC Health Service Research 2014.

31. World Health Organization. Classification of diabetes mellitus. 2019.

32. Levey, A. A simplified equation to predict glomerular filtration rate from serum creatinine. Journal of the American Society of Nephrology 2000, 11, A0828.

33. Levey, A.S.; Coresh, J.; Balk, E.; Kausz, A.T.; Levin, A.; Steffes, M.W.; Hogg, R.J.; Perrone, R.D.; Lau, J.; Eknoyan, G. National Kidney Foundation practice guidelines for chronic kidney disease: evaluation, classification, and stratification. Annals of Internal Medicine 2003, 139, 137-147.

34. Zaman, S.B.; Gupta, R.D.; Pramual, P.; Khan, R.K.; Sujimongkol, C.; Hossain, N.; Haider, M.R.; Karim, M.N.; Kibria, G.M.; Islam, S.M.S. The burden of chronic kidney disease among people with diabetes by insurance schemes: findings from a primary referral hospital in Thailand. Diabetes Epidemiology and Management 2021, 100026.

35. Thakur, S.K.; Dhakal, S.P.; Parajuli, S.; Sah, A.K.; Nepal, S.P.; Paudel, B.D. Microalbuminuria and its risk factors in type 2 diabetic patients. Journal of Nepal Health Research Council 2019, 17, 61-65.

36. Ahmad, T.; Ulhaq, I.; Mawani, M.; Islam, N. Microalbuminuria in Type-2 Diabetes Mellitus; the tip of iceberg of diabetic complications. Pakistan Journal of Medical Sciences 2017, 33, 519.

37. Janmohamed, M.N.; Kalluvya, S.E.; Mueller, A.; Kabangila, R.; Smart, L.R.; Downs, J.A.; Peck, R.N. Prevalence of chronic kidney disease in diabetic adult out-patients in Tanzania. BMC Nephrology 2013, 14, 183.

38. Parving, H.-H.; Lewis, J.; Ravid, M.; Remuzzi, G.; Hunsicker, L. Prevalence and risk factors for microalbuminuria in a referred cohort of type II diabetic patients: a global perspective. Kidney International 2006, 69, 2057-2063.

39. Chen, J.; Gu, D.; Chen, C.-S.; Wu, X.; Hamm, L.L.; Muntner, P.; Batuman, V.; Lee, C.-H.; Whelton, P.K.; He, J. Association between the metabolic syndrome and chronic kidney disease in Chinese adults. Nephrology Dialysis Transplantation 2007, 22, 1100-1106.

40. Islam, S.M.S.; Islam, M.T.; Uddin, R.; Tansi, T.; Talukder, S.; Sarker, F.; Mamun, K.A.A.; Adibi, S.; Rawal, L.B. Factors associated with low medication adherence in patients with Type 2 diabetes mellitus attending a tertiary hospital in Bangladesh. Lifestyle Medicine 2021, 2, e47. 
41. Islam, S.M.S.; Biswas, T.; Bhuiyan, F.A.; Mustafa, K.; Islam, A. Patients' perspective of disease and medication adherence for type 2 diabetes in an urban area in Bangladesh: a qualitative study. BMC Research Notes 2017, 10, 1-8.

42. Islam, S.M.S.; Ahmed, S.; Uddin, R.; Siddiqui, M.U.; Malekahmadi, M.; Al Mamun, A.; Alizadehsani, R.; Khosravi, A.; Nahavandi, S. Cardiovascular diseases risk prediction in patients with diabetes: Posthoc analysis from a matched case-control study in Bangladesh. Journal of Diabetes E Metabolic Disorders 2021, 20, 417-425.

43. Lin, C.-H.; Yang, W.-C.; Tsai, S.-T.; Tung, T.-H.; Chou, P. A community-based study of chronic kidney disease among type 2 diabetics in Kinmen, Taiwan. Diabetes Research and Clinical Practice 2007, 75, 306-312.

44. Afkhami-Ardekani, M.; Modarresi, M.; Amirchaghmaghi, E. Prevalence of microalbuminuria and its risk factors in type 2 diabetic patients. Indian Journal of Nephrology 2008, 18, 112.

45. Ko, G.T.; Chan, J.C.; Lau, M.; Cockram, C.S. Diabetic microangiopathic complications in young Chinese diabetic patients: a clinic-based cross-sectional study. Journal of Diabetes and its Complications 1999, 13, 300-306.

46. George, C.; Mogueo, A.; Okpechi, I.; Echouffo-Tcheugui, J.B.; Kengne, A.P. Chronic kidney disease in low-income to middleincome countries: the case for increased screening. BMJ Global Health 2017, 2.

47. Hossain, M.P.; Goyder, E.C.; Rigby, J.E.; El Nahas, M. CKD and poverty: a growing global challenge. American Journal of Kidney Diseases 2009, 53, 166-174.

48. Islam, S.M.S.; Mainuddin, A.; Islam, M.S.; Karim, M.A.; Mou, S.Z.; Arefin, S.; Chowdhury, K.N. Prevalence of risk factors for hypertension: A cross-sectional study in an urban area of Bangladesh. Global Cardiology Science and Practice 2015, $2015,43$.

49. Islam, S.M.S.; Lechner, A.; Ferrari, U.; Laxy, M.; Seissler, J.; Brown, J.; Niessen, L.W.; Holle, R. Healthcare use and expen diture for diabetes in Bangladesh. BMJ Global Health 2017, 2, e000033.

50. Rajapurkar, M.M.; John, G.T.; Kirpalani, A.L.; Abraham, G.; Agarwal, S.K.; Almeida, A.F.; Gang, S.; Gupta, A.; Modi, G.; Pahari, D. What do we know about chronic kidney disease in India: first report of the Indian CKD registry. BMC Nephrology 2012, 13, 10.

51. Thomas, M.C.; Cooper, M.E.; Zimmet, P. Changing epidemiology of type 2 diabetes mellitus and associated chronic kidney disease. Nature Reviews Nephrology 2016, 12, 73.

52. Chadban, S.J.; Briganti, E.M.; Kerr, P.G.; Dunstan, D.W.; Welborn, T.A.; Zimmet, P.Z.; Atkins, R.C. Prevalence of kidney damage in Australian adults: The AusDiab kidney study. Journal of the American Society of Nephrology 2003, 14, S131-S138.

53. Idowu, A.A.; Ajose, A.O.; Adedeji, A.T.; Adegoke, A.O.; Jimoh, K.A. Microalbuminuria, Other Markers of Nephropathy and Biochemical Derangements in Type 2 Diabetes Mellitus: Relationships and Determinants. Ghana Medical Journal 2017, 51, 5663.

54. Varghese, A.; Deepa, R.; Rema, M.; Mohan, V. Prevalence of microalbuminuria in type 2 diabetes mellitus at a diabetes centre in southern India. Postgraduate Medical Journal 2001, 77, 399-402.

55. Safita, N.; Islam, S.M.S.; Chow, C.K.; Niessen, L.; Lechner, A.; Holle, R.; Laxy, M. The impact of type 2 diabetes on health related quality of life in Bangladesh: results from a matched study comparing treated cases with non-diabetic controls. Health and Quality of Life Outcomes 2016, 14, 1-9.

56. Moses, J.C.; Adibi, S.; Shariful Islam, S.M.; Wickramasinghe, N.; Nguyen, L. Application of Smartphone Technologies in Disease Monitoring: A Systematic Review. Healthcare 2021, 9, 889.

57. Islam, S.M.S.; Maddison, R. Digital health approaches for cardiovascular diseases prevention and management: lessons from preliminary studies. Mhealth 2021, 7.

58. Islam, S.M.S.; Farmer, A.J.; Bobrow, K.; Maddison, R.; Whittaker, R.; Dale, L.A.P.; Lechner, A.; Lear, S.; Eapen, Z.; Niessen, L.W. Mobile phone text-messaging interventions aimed to prevent cardiovascular diseases (Text2PreventCVD): systematic review and individual patient data meta-analysis. Open Heart 2019, 6, e001017.

59. Islam, F.M.A.; Lambert, E.A.; Islam, S.M.S.; Islam, M.A.; Biswas, D.; McDonald, R.; Maddison, R.; Thompson, B.; Lambert, G.W. Lowering blood pressure by changing lifestyle through a motivational education program: A cluster randomized controlled trial study protocol. Trials 2021, 22, 1-11. 
60. Frost, D.; Mahmud, M.; Kaiser, M.S.; Musoke, D.; Henry, P.; Islam, S.M.S. Innovative Approaches to Strengthening Health Systems in Low-and Middle-Income countries: Current Models, Developments, and Challenges. Health Policy and Technology 2021, 10, 100567.

61. Islam, S.; Chow, C.; Redfern, J.; Kok, C.; Rådholm, K.; Stepien, S.; Rodgers, A.; Hackett, M. Effect of text messaging on depression in patients with coronary heart disease: A sub study analysis from the TEXT ME randomised controlled trial. BMJ Open 2019.

62. Islam, S.; Tabassum, R.; Liu, Y.; Chen, S.; Redfern, J.; Kim, S.; Ball, K.; Maddison, R.; Chow, C. The role of social media in preventing and managing non-communicable diseases in low-and-middle income countries: Hope or Hype? Health Policy and Technology 2019. 